\title{
Modeling Business Strategy: A Consumer Value Perspective
}

\author{
Eric-Oluf Svee, Constantinos Giannoulis, and Jelena Zdravkovic \\ Department of Computer and Systems Sciences \\ Stockholm University \\ Forum 100, SE-164 40 Kista, Sweden \\ \{eric-sve, constantinos, jelenaz\}@dsv.su.se
}

\begin{abstract}
Business strategy lays out the plan of an enterprise to achieve its vision by providing value to its customers. Typically, business strategy focuses on economic value and its relevant exchanges with customers and does not directly address consumer values. However, consumer values drive customers' choices and decisions to use a product or service, and therefore should have a direct impact on business strategy. This paper explores whether and how consumer values influence business strategy, and how they might be linked to IS solutions that support the implementation of such strategies. To address these questions, the study maps consumer values to a business strategy approach via a meta-model commonly used for such purposes, based on strategy maps and balanced scorecards (SMBSC). Additionally, the applicability of the mappings is illustrated via a case scenario where the mappings are applied and the business strategy conceptualization captures them. Finally, based on these mappings, high level guidelines for linking consumer values to requirements for the development of IS solutions through business strategy conceptualization are proposed.
\end{abstract}

Keywords: Consumer value, strategy maps, balanced scorecards, requirements engineering.

\section{Introduction}

The ability of an enterprise to attain its vision is dependent primarily on its capability to efficiently marshal and align its resources, compete within a sustainable environment, and strive for innovation to aid in executing its business strategy. However, while the basis for much of this work is related to the interactions with the enterprise's customers, this vital and necessary connection between the two often lacks the rigor and structure necessary to elicit the desires of the customer and deliver them to the enterprise.

The importance of customer desires has long been acknowledged, as Morris [1] claims that all products provide services in their capacity to create the need of wantsatisfying experiences. Drucker [2] claims that in addition to harmonizing the utilization of its resources, an enterprise should focus on the opportunities to create 
revenue by re-shaping the characteristics of existing services and products to satisfy its customers. Such customer desires have been typically addressed as economic values such as goods, services, money, and information. However, another perspective of customer desires, namely consumer value, has not been explored. A consumer value is a personal norm: a belief about what is needed, wanted, or ought to be, which serves as a guide to consumers in making decisions [3].

Therefore, any disconnection between consumer value and business strategy can prove problematic. For example, a bank might provide a robust e-banking system which is unappealing and unusable to the end-user. However, while the system satisfies the bank's needs, but not those of its customers, it will not be successfully adopted. Unfortunately, current approaches to business strategy do not explicitly capture the values regarding products and services that come directly from consumers.

The goal of this paper is to explore whether and how consumer values influence business strategy and consequently how this influence reflects on IS solutions that are operationalized to support business strategy implementation.

Given the numerous business strategy approaches available (e.g. Strategy Maps and Balanced Scorecards [4], the Value Chain [5], Blue Ocean Strategy [6], etc.) and the different approaches on consumer values (e.g. Holbrook's Typology [3], Quantification of values [7], Rokeach's Value Survey [8], Schwartz's Value Survey (SVS) [9], etc.), in this study we choose to explore prevalent approaches in both areas and, particularly for business strategy, approaches that include some level of conceptualization or formalism that can support traceability. Therefore, we use Holbrook's Typology of Consumer Values for capturing and structuring the desires and aspirations of consumers [3], and Strategy Maps and Balanced Scorecards as a business strategy approach [4], which is conceptualized in the means of a meta-model [10].

This paper is structured as follows: Section 2 provides an overview of Holbrook's Typology of Consumer Values as well as Strategy Maps and Balanced Scorecards (SMBSC). Section 3 presents our contribution, the mappings of Holbrook's consumer values to Strategy Maps and the SMBSC meta-model. Section 4 illustrates our contribution using a case scenario of a shopping mall. Section 5 outlines the links of our contribution to requirements engineering and Section 6 summarizes our conclusions and indicates the steps forward.

\section{Related Work}

\subsection{Consumer Values}

Holbrook refines the value concept, focusing on those held by individuals during a value exchange: consumer values. Consumer values are "an interactive, relativistic preference experience" [3]. Unpacking this definition, one finds that interactive entails an interaction between some subject and an object. Next, relative refers to consumer values being comparative, involving preferences among objects, varying across people, and they are situational, or context specific. Preferential refers to consumer values embodying the outcome of an evaluative judgment, where something is more or less desirable in comparison to something else, and finally 
experience refers to consumer values not residing in the product purchased, brand chosen, or object possessed, but in the consumption experience. This allows for a rather expansive view of value, because all products provide services in their capacity to create need- or want- satisfying experiences.

Dimensions of Consumer Values. Holbrook identifies three dimensions in consumer values [3].

Extrinsic/Intrinsic. Extrinsic is a means/end relationship wherein consumption is prized for its functional, utilitarian ability to serve as a means to accomplish some further purpose, aim, goal, or objective. For example, hammers are generally prized for their utility and not their beauty. Intrinsic occurs when some consumption experience is appreciated as an end in itself-for its own sake-such as listening to music.

Orientation. Self-oriented is when some aspect of consumption is cherished, either selfishly or prudently, for the individual's sake; a sweater has value partly because it keeps its owner warm. Other-oriented is where the consumption experience or the product on which it depends is valued by others, either beyond the subject, for its own sake, for how they react to it, or for the effect it has on them. For example, a Ferrari might be purchased to impress someone's co-workers.

Activity. Active entails a physical or mental manipulation of some tangible or intangible object, involving things done by a consumer to or with a product as part of some consumption experience: driving a Ferrari is part of what makes owning one desirable. Reactive results from apprehending, appreciating, admiring, or otherwise responding to an object, when the object acts upon the subject. Similar to the example given for intrinsic, listening to music can also be reactive, when the consumptive act is driven by the object and not the subject.

Typology of Consumer Values. Based on these three dimensions, Holbrook creates his Typology of Consumer Values where each archetype (author's term) represents a distinct type of value in the consumption experience [3].

Efficiency results from the active use of a product or consumption experience as a means to achieve some self-oriented purpose. This is a utilitarian value: recall that hammers are generally prized for their usefulness and not their beauty. Often, Efficiency is measured as a ratio of outputs to inputs. For example, the Efficiency of an automobile can be assessed as some ratio of distance traveled to volume of fuel used. Another view of Efficiency — convenience—is often a measure of utility derived versus time or energy expended. With Excellence, one admires some object or prizes some experience for its capacity to accomplish some goal or to perform some function: a Ferrari is a wonderful choice for a high-quality automobile, though a poor choice for a delivery truck. Status is sought by adjusting consumption in a manner that affects those whom one wishes to influence, consuming products or engaging in consumption experiences so as to project a particular type of image one wishes to portray. In other words, consumption is about communicating about ones' self to others in ways that contribute to success. Status and Esteem are intimately 
interrelated, with Esteem the reactive counterpart to Status. Esteem tends to result from a somewhat passive ownership of possessions appreciated as a means to building one's reputation with others. In other words, Esteem is about the reactive appreciation of consumption or lifestyle in a somewhat passive way as a potential extrinsic means to enhancing my other-oriented public image. Play is a self-oriented experience - actively sought and enjoyed for its own sake — and as such, typically involves having fun. Aesthetics refers to an appreciation of some consumption experience valued intrinsically as a self-oriented end in itself. The hallmark of this value is that it is enjoyed for its own sake, without a need for external justification. Ethics involves doing something for the sake of others- that is, with a concern for how it will affect them or how they will react to it - where such consumption experiences are valued for their own sake as ends in themselves. Donating blood is an activity that is not often done for selfish benefits, but rather is most often motivated by selfless reasons. Spirituality entails an intrinsically motivated acceptance, adoption, appreciation, admiration, or adoration of an Other where this "Other" may constitute some Divine Power, or some otherwise inaccessible Inner Being. Such an experience is sought not as a means to an ulterior end but rather as an end in itself prized for its own sake. People often donate money to churches for the sole purpose of feeling closer to just such an Other.

\subsection{Strategy Maps and Balanced Scorecards}

A strategy map is a general representation of the four organizational perspectives of the balanced scorecards in a cause-effect manner and facilitates the communication of direction and priorities across the enterprise according to [11].

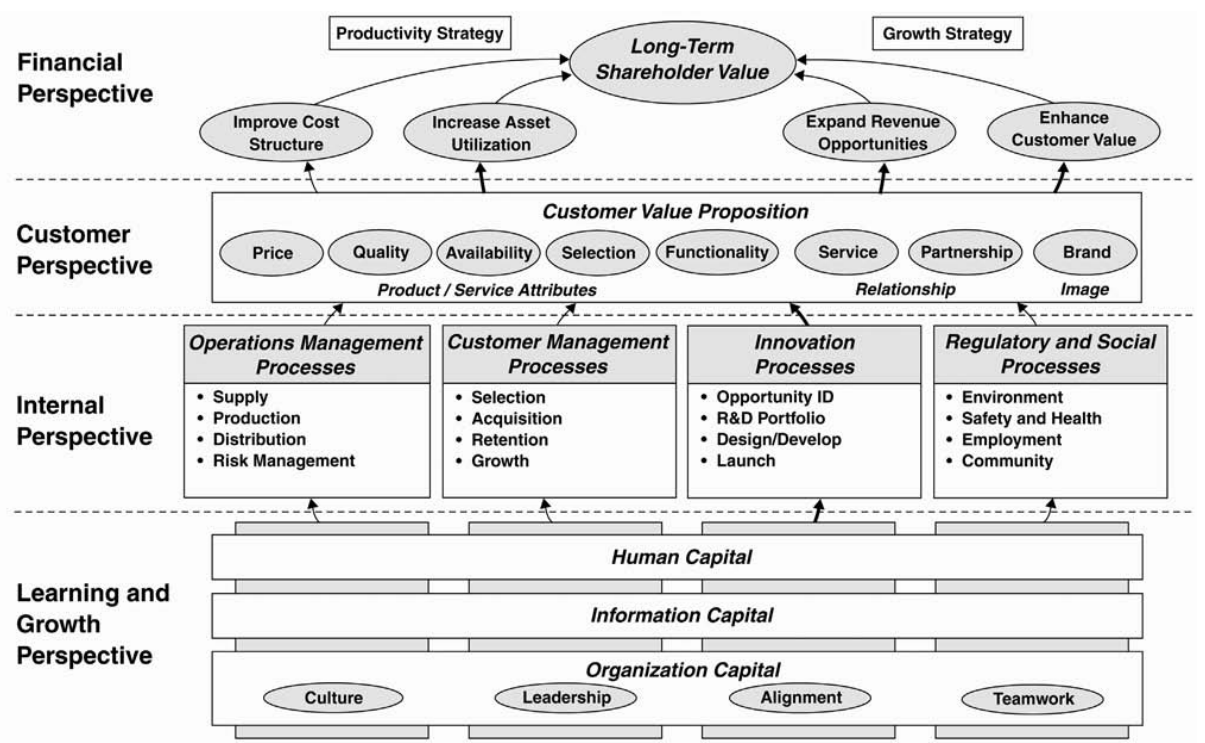

Fig. 1. The Strategy Map template [4] 
Strategy balances long-term financial commitments aims at profitable revenue growth and short-term financial commitments aiming at cost reductions and productivity improvements (financial perspective). Strategy is based on a differentiated and clearly articulated customer value proposition (customer perspective). Value is created through focused, effective, and aligned internal business processes grouped into four clusters: operations management, customer management, innovation, and regulatory-social (internal perspective). Strategy consists of simultaneous, complementary themes highlighting the most critical processes supporting the customer value proposition. Strategic alignment determines the value and role of intangible assets, which includes human, information, and organization (learning and growth perspective).

A strategy map serves as a mediator between the mission, core values, the vision, and the strategy of an enterprise to the work performed. Kaplan and Norton have proposed a template for strategy maps representing how an organization can create value (Figure 1). Starting from a mission statement and core values, a strategic vision is defined, which should project the organization's overall goal. A set of goals are defined and initially grouped within the financial and customer perspectives. For the internal perspective, as well as the learning and growth perspective, we consider that both processes and capital appear in a strategy map in the form of goals, which through cause-effect relationships, support goals at the customer perspective. Similarly, goals are set for all groups of capital referring to particular asset categories defining desired competencies, capabilities needed to support internal processes [12].

Scorecards consist of strategic objectives and related measures, which include concrete targets and initiatives towards their achievement [13] and are structured with cause-effect links/assumptions whose monitoring and assessment is essential for identifying interdependencies across an organization. According to [14], a balanced scorecard presents an organization's business activities through a number of measures, typically from four organizational perspectives: financial, customer, internal, learning and growth, and provides a language to communicate priorities within an enterprise. When the four perspectives are addressed, providing complete coverage of business processes, a scorecard is considered balanced. While the time aspect is addressed indirectly via short-term targets set and also via the bottom up view of the four perspectives suggesting that what lies on the bottom is the outcome of planning at the top and is a prerequisite. Additionally a scorecard is also considered balanced because it covers both the internal as well as the external aspects of an enterprise.

\section{Enriching Business Strategy with Consumer Values}

In this section we present how strategy maps can be enriched by consumer values. In the first part we link strategy map goals to Holbrook's consumer value typology while in the second part we extend the SMBSC meta-model to incorporate goals reflecting consumer values. 


\subsection{Relating Consumer Values to Strategy Maps}

Anticipating customers' needs is addressed in the customer perspective of strategy maps, where the customer value proposition is defined. Kaplan and Norton identify four generic strategies for defining the customer value proposition [4]. These are: Low Total Cost, where products and services are offered that are consistent, timely, and low-cost; Product Leadership, which offers products and services that expand existing performance boundaries into the highly desirable; Complete Customer Solutions, designed to provide the best total solution to our customers; and System Lock-In, where high switching costs maintain end-users as customers. Additionally, for each customer value proposition strategy a set of generic goals is defined.

In this study, we analyze Complete Customer Solutions as a possible example of a customer value proposition, which emphasizes building long-lasting relationships with customers [4].

The customer value proposition of Complete Customer Solution aims to provide the best total solution to customers, and it includes the following general goals (originally named objectives): Quality of Solutions Provided to Customers, Number of Products and Services per Customer, Customer Retention, and Lifetime Customer Profitability. Therefore, we analyze them one by one and identify which consumer values are relevant to the enhancement of strategy maps, and those which are not.

Table 1. Customer Perspective Goals for Complete Customer Solutions and their related Consumer Values

\begin{tabular}{l|cccc}
\hline \multirow{2}{*}{$\begin{array}{l}\text { Consumer } \\
\text { Value }\end{array}$} & \multicolumn{4}{|c}{ Customer Perspective Goals } \\
\cline { 2 - 5 } & Number of Products \& & Quality of Solutions & Lifetime Customer & Customer \\
& Services per Customer & Provided to Customers & Profitability & Retention \\
\hline Efficiency & $\sqrt{ }$ & $\sqrt{ }$ & $\sqrt{ }$ & $\sqrt{ }$ \\
Excellence & $\sqrt{ }$ & $\sqrt{ }$ & $\sqrt{ }$ & $\sqrt{ }$ \\
Play & & $\sqrt{ }$ & $\sqrt{ }$ & $\sqrt{ }$ \\
Aesthetics & & $\sqrt{ }$ & $\sqrt{ }$ \\
Status & & & & $\sqrt{ }$ \\
Esteem & & $\sqrt{ }$ & $\sqrt{ }$ \\
Ethics & & & & $\sqrt{ }$ \\
Spirituality & & & &
\end{tabular}

Number of Products and Services per Customer. Superior product functionality, relating to matters such as speed, accuracy, and power, lies at the heart of high quality products. Two of Holbrook's consumer values are directly related to this: Efficiency and Excellence. From the consumer perspective, such a product is most likely to be both Efficient, where its active use allows for accomplishing some self-oriented purpose, as well as Excellent, where the product is admired for its intrinsic abilities to accomplish some end. An automobile allows someone to travel more quickly (Efficient) but the experience of driving one of high quality has a different level of appreciation for the consumer (Excellent) than driving one of lower quality. 
Quality of Solutions Provided to Customers and Lifetime Customer Profitability. These objectives entail a deep understanding about what customers value, and combine it with the ability to bundle products into individually customized solutions. These objectives speak to the completeness of a solution, and are most closely related to the Holbrook's archetypes Efficiency, Excellence, Play, Aesthetics, and Esteem.

As an example, the utilitarian focus of Efficiency can be found in the time savings a customer would accrue by shopping via the new online portal of a business as opposed to the brick-and-mortar location of a competitor. For example, Amazon grew to prominence by being the prime mover in a retail space (book selling) that had not undergone a shift to online sales. Amazon now offers many products for sale, and has numerous purchasing and delivery options from physical goods to music downloads. It offers a complete, individually tailored solution to its customers, one that continues to grow and evolve over time.

Excellence is also utilitarian, but, according to Holbrook's dimensions, it is reactive rather than active. In comparing the actual experience with the expectations for that experience, Excellence relates closely to the concept of satisfaction and appears to constitute the essence of what is generally understood as quality [3]. In the case of a purchasing a book from Amazon, the customer could experience an innate sense of satisfaction based on the quality of the entire shopping experience, taking into account the efficiency-accrued time savings, among other benefits.

Play and its counterpart Aesthetics could also be related to high performance products. Product enjoyment, either based on direct use of the product or via an appreciation of its overall design, is seen as relating to these. Apple products command a premium in the marketplace, to a large extent because consumers derive pleasure both from using their well-designed products, as well as having a general appreciation for their appearance and Aesthetics.

Esteem is an internally directed idea, whereby the consumer has a selfcongratulatory moment for having purchased a particular item, similar to the saying that "No one was ever fired for hiring IBM". Although the veracity of the statement might be questioned, the general premise is that, while IBM is not known for producing the most technologically advanced, the most powerful, or the fastest products, it is widely respected for providing a complete customer solution-from hardware, to software, to training-delivered in a customized solution.

Customer Retention. As Kaplan and Norton state, this objective is about the quality of relationships. Exceptional service is involved, making it critical that the organization has access to a diverse array of capabilities to develop the best means to serve their customers. Thus, all eight consumer values are needed to acquire and develop new customer segments, as well as to enrich and deepen those relationships. In addition to the five that have been previously discussed (Efficiency, Excellence, Play, Aesthetics and Esteem), the three remaining (Status, Ethics, Spirituality) can also play an important role in the process.

Status is important to this segment, as early adopters are one of the primary targets for customer engagement. By displaying the latest and greatest, consumers are often seeking to display various personal characteristics (intelligence, success) through the medium of the object. 
Ethics and Spirituality can be very powerful consumer values, but they can be difficult to work with and must be handled with great care and delicacy, particularly Spirituality. And while it might be considered a great leap to include them in this objective, it is important to view them solely as possible means to achieve it. Whereas Ethics is driven by a selfless motivation, Spirituality is self-directed.

\subsection{Consumer Value-Enhanced SMBSC Meta-model}

In [10] the conceptualization of strategy maps and balanced scorecards in the means of a meta-model was presented, accompanied by a set of constraints. To support the mappings of consumer values to the four strategies of the customer value proposition proposed by Kaplan and Norton, the SMBSC meta-model must be updated.

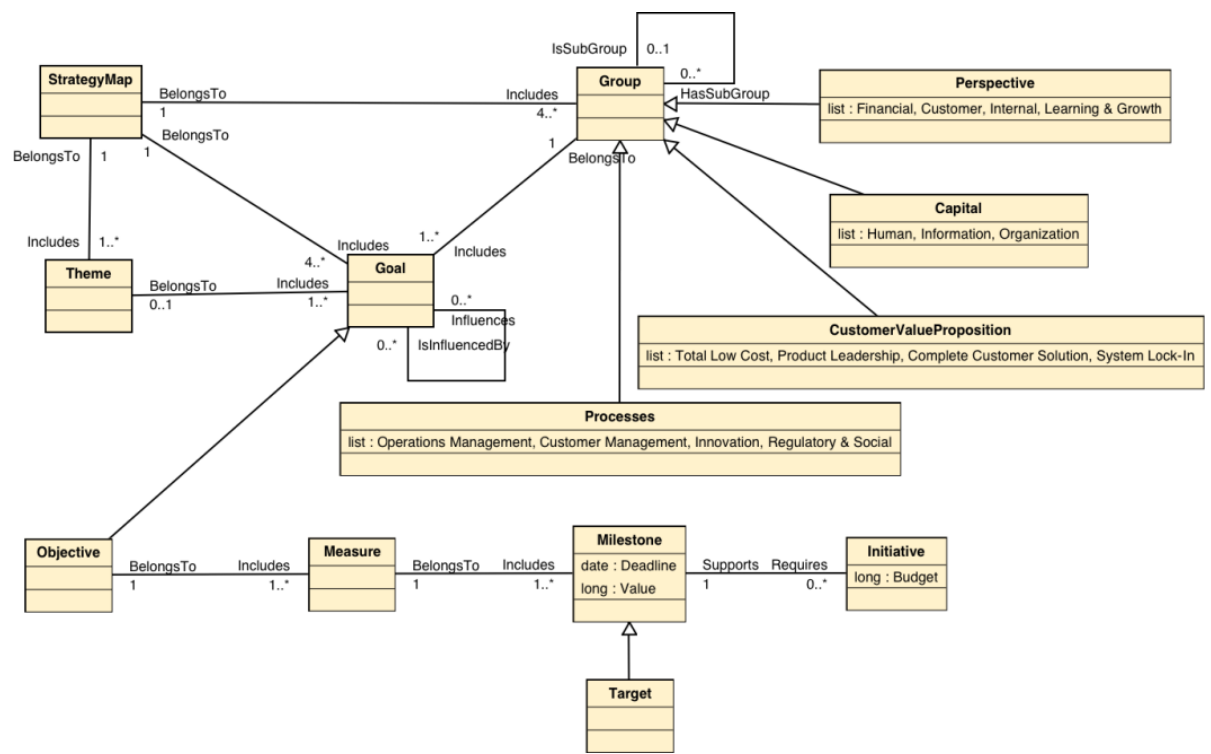

Fig. 2. The updated SMBSC meta-model

The updates refer to the substitution of the GroupType class into concrete groupings found in the template and Kaplan and Norton's original writings and refer to sub-groups of perspectives (e.g. for the customer perspective sub-groupings include the four customer value propositions). These sub-groupings are accompanied by additional constraints. For example an instance of CustomerValueProposition can only be a sub-group of Perspective:Customer, while an instance of the Processes can only be a sub-group of Perspective:Internal, etc. Figure 2 presents the updated SMBSC meta-model.

The four different strategies for defining Customer Value Proposition [4] — Low Total Cost, Product Leadership, Complete Customer Solution and System Lock-in] are introduced in the SMBSC meta-model through a specialization of the class Group, the Customer Value Proposition class. The Customer Value Proposition class is 
constrained through the IsSubGroup association of the Group class to be sub-group of a group which is a Perspective and particularly of the type Customer.

In accordance to the strategy map template, the generic goals proposed by Kaplan and Norton reflect the customer value proposition chosen and constitute a grouping of goals within the customer perspective. In the meta-model, this is captured by each generic Goal belonging to the group CustomerValueProposition, which can be of type of one of the four strategies defined. Moreover, the group CustomerValueProposition, through the IsSubGroup association, is a sub-group of the group Perspective which is of type Customer. Therefore, similarly to the previous section, we examine product leadership, which includes three generic goals: First to Market, High Performance Products, and New Market Segments. Each of these goals are instances of the Goal class belonging to the instance of Complete Customer Solution of the Customer Value Proposition class which is a Group, and through the IsSubGroup association it is a sub-group of Customer, which is an instance of Perspective which is a Group.

Based on the mappings of consumer values to customer value proposition strategies provided in 3.1, the SMBSC meta-model provides traceability of consumer values from strategy maps (goals) to balanced scorecards. A Goal is expressed as an Objective when an appropriate Measure to demonstrate its achievement can be defined. An Initiative encompasses all actions identified as required towards the achievement of the objective, within the constraints of given Milestones and Targets. Additionally, mapping consumer values to goals in strategy maps makes them potentially measurable (not all goals are measurable), allowing the derivation of initiatives through balanced scorecards.

\section{Case Scenario}

In this section a case scenario is used to illustrate our contribution: a general strategy map of a shopping mall that has been enhanced by Holbrook's Typology of Consumer Values. To accomplish this, the customer objectives for Kaplan and Norton's strategy map template for Product Leadership are applied to a scenario that explores the development of a shopping map [15] along with and their related consumer values

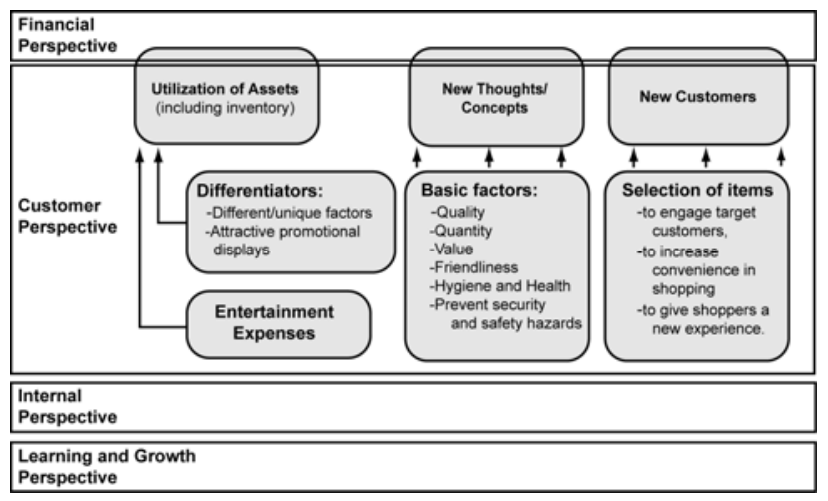

Fig. 3. Excerpt from the shopping mall strategy map found in [15] 
and mappings as proposed in earlier. The strategy map from the shopping mall (Figure 3) is used to illustrate the proposed mappings, and more specifically to illustrate whether, and how, consumer values influence product leadership.

So what exactly would a strategy map look like for a shopping mall that wanted to become a product leader by adopting Kaplan and Norton's strategy map? According to the case scenario the mall's developers already plan to change their value proposition from an operational experience to one of customer convenience and intimacy. The updated customer value proposition for such a shopping mall would be that "the mall differentiates itself by offering a unique shopping experience, built on customer convenience and intimacy, occurring under one roof". However, the developers of the property did not made any provisions for incorporating what consumers actually want their experience to be in the shopping mall into the strategy map that they are creating.

\subsection{Mapping Consumer Values to the Case Scenario}

For the shopping mall case, we are mapping the consumer values from [16] to the Complete Customer Solution goals found in [15]. Table 2 first displays a consumer value from Holbrook, followed by a shopping value that exemplifies it. This in turn is supported by examples from marketing research, and these in turn are compared to the strategy map provided in the scenario. These were then judged on their level of implementation with three possible marks: a '-' was given if the shopping value was completely missing from the strategy map, a ' $*$ ' was given if a shopping value was partially missing from the strategy map, and a ' + ' was given if there was a complete implementation within the strategy map.

Of the 31 shopping values presented, nine were found to have been completely implemented in the strategy map (29\%), 14 were partially implemented (45\%) and eight were not implemented at all (26\%). This leaves $71 \%$ as an area for at least partial improvement, a significant number. And as shown previously, the close linkage between consumer values and consumer intent provides a compelling case for implementing a consumer value driven strategy; if their values are taken into account, consumers are more likely to make purchases. The ability to convert these values into concrete goals and objectives which the business can deliver on, often through improved alignment with IT, is enhanced through the use of the new meta-model.

Example of a value completely missing from the Strategy Map. Consumers were clear that, in terms of an efficient use of their resources (time, effort, money, etc) a key concern was access to the mall. Issues such as transportation to the mall, traffic encountered in the journey, and parking, were all important issues that the research highlighted. These are not addressed anywhere in the original strategy map.

Example of a value partially missing from the Strategy Map. The scenario speaks to high levels of staff training and has an explicit goal of Friendliness. While a laudable goal, details found in the consumer research reveal the 'right' way to implement such a strategy. Consumers stated that they did not want to spend energy dealing with pushy salespeople. However, unless this value is captured and populated further in the 
development process, this valuable detail could be lost. There is a fine line between friendly and obsequious, and care must be taken to ensure that the true intentions of the consumer are addressed.

Table 2. Mapping Consumer Values to the Shopping Mall Case Scenario

\begin{tabular}{|c|c|c|c|c|}
\hline $\begin{array}{l}\text { Consumer } \\
\text { Value }\end{array}$ & $\begin{array}{l}\text { Shopping } \\
\text { Value }\end{array}$ & $\begin{array}{l}\text { Mall Shopping } \\
\text { Value }\end{array}$ & $\begin{array}{c}\text { Shopping } \\
\text { Mall Strategy } \\
\text { Map }\end{array}$ & $\begin{array}{c}\text { Complete Customer } \\
\text { Solutions }\end{array}$ \\
\hline \multirow[t]{10}{*}{ Efficiency } & \multirow[t]{3}{*}{ Convenience } & One stop shopping & + & \# of Products \\
\hline & & Comparison shopping & $*$ & \# of Products \\
\hline & & Multi-purpose shopping & $*$ & Quality \\
\hline & \multirow{3}{*}{$\begin{array}{l}\text { Resources } \\
\text { (Time/Effort } \\
\text { Money) }\end{array}$} & Transportation & - & Quality \\
\hline & & Traffic & - & Quality \\
\hline & & Parking & - & Quality \\
\hline & & Time spent in mall & $*$ & Quality \\
\hline & & Pushy Sales people & $*$ & Quality \\
\hline & & Finding desired product & + & Quality \\
\hline & & $\begin{array}{l}\text { Waiting in check-out } \\
\text { lines }\end{array}$ & $*$ & Quality \\
\hline \multirow[t]{5}{*}{ Excellence } & \multirow{2}{*}{$\begin{array}{l}\text { Customer } \\
\text { Service }\end{array}$} & Human contact & $*$ & Retention \\
\hline & & Safe \& secure shopping & + & Quality \\
\hline & \multirow{3}{*}{$\begin{array}{l}\text { Product } \\
\text { Performance }\end{array}$} & Quality & + & Quality \\
\hline & & Selection & + & \# of Products \\
\hline & & Price & + & Quality \\
\hline \multirow[t]{13}{*}{ Play } & \multirow{2}{*}{$\begin{array}{l}\text { Sensory } \\
\text { stimulation }\end{array}$} & \multirow{4}{*}{$\begin{array}{l}\text { Appeal to five senses } \\
\text { Instant gratification } \\
\text { Entertainment centers } \\
\text { Cinema }\end{array}$} & + & Retention \\
\hline & & & * & \# of Products \\
\hline & & & $*$ & Retention \\
\hline & & & - & Retention \\
\hline & & Games & - & Retention \\
\hline & & Eateries & + & Retention \\
\hline & & Special events/exhibits & $*$ & Retention \\
\hline & & Walking for exercise & - & Retention \\
\hline & & Window shopping & $*$ & Quality \\
\hline & \multirow{4}{*}{\begin{tabular}{|l} 
Social \\
Interaction \\
\end{tabular}} & People watching & $*$ & Quality \\
\hline & & Socializing with friends & $*$ & Quality \\
\hline & & $\begin{array}{l}\text { Talking with other } \\
\text { shoppers }\end{array}$ & $*$ & Quality \\
\hline & & Escaping from routine & + & Quality \\
\hline \multirow[t]{3}{*}{ Aesthetics } & \multirow[t]{3}{*}{ Ambience } & Architecture & - & Retention \\
\hline & & Interiors & - & Retention \\
\hline & & Visual display & $*$ & Retention \\
\hline
\end{tabular}


Example of a value completely implemented by the Strategy Map. Ideas about Quality, Selection, and Price cut across many aspects of the shopping mall strategy map, and are also directly applicable to the generic Complete Customer Solutions map. In fact, these are some of the primary drivers behind each of the three customer objectives found in that map: First to Market, High Performance Products, and New Customer Segments.

Esteem is closely related to Status, differing only slightly in its perspective. In the scenario, the customer experience is designed to be one that the customer appreciates deeply on several levels: the shopping mall is family-friendly environment in which to easily and efficiently acquire high-quality items at competitive prices. This complete experience is something that the consumer could appreciate reflectively, taking pleasure from the superior physical environment as well as their own business acumen: how smart of them for getting such a good deal. The developer of the shopping mall could decide to build on this experience, perhaps adding components to the experience that could develop Status (e.g., higher end retailers).

\subsection{Instantiating the Meta-model for the Shopping Mall}

The shopping mall strategy map (Figure 3) is in accordance to Kaplan and Norton's template and its conceptualization, the SMBSC meta-model [10] adhering to the constraints defined. For example, the New Thoughts/Concepts, which is a group of goals (product/service attributes in the original SM template) within the customer perspective, then each goal on Quality, Quantity, Value, Friendliness, Hygiene \& Health, Prevent security \& safety hazards belongs to the group New Thoughts/Concepts of GroupType Service Attribute (one of the groupings identified within the original SM template), which is a sub-group of the Perspective Customer Perspective. Each of these goals belongs to the shopping mall strategy map.

To illustrate how the meta-model can instantiate the mappings of section 4.1 we use a concrete example of a consumer value. Therefore, based on [16] and table 3, one stop shopping is identified as a mall shopping value, related to the shopping value of Convenience which is mapped to the consumer value of Efficiency and it is related to the generic goal of Number of Products per Customer. Therefore, one stop shopping is a goal:

- belonging to the shopping mall strategy map, through the BelongsTo association to StrategyMap,

- influencing the goal Number of Products per Customer, through the Influences association to Goal,

- belonging to the group Customer Value Proposition of type Complete Customer Solution, which through the IsSubGroup association to Group, is a subgroup of the group Perspective of type Customer.

\section{$5 \quad$ Link to Requirements Engineering}

Once a SMBSC model is created, it can be used to guide activities for an IS department via high-level requirements for new software solutions that will support 
the operationalization of the created strategy model. One possible approach here is to map the strategy concepts to those of a certain Requirements Engineering (RE) technique, such as Goal-Oriented Requirements Engineering, (GORE) [17], ScenarioOriented RE (SCORE) [18], among others.

In the SMBSC framework the notion of goal is used to capture the aims of a company from the four different perspectives. In some of the requirements engineering techniques, such as in GORE, the notion of system goal stating the intent underpinning a system service, or a quality/constraint on the service provisioning, is used as a starting point when discovering system requirements. Thereby, even the goals are considered differently in business strategy and requirements engineering approaches, a possible starting point for propagating the results of a SMBSC model to a requirements engineering model is through goals. The effect of the alignment is two-fold: from the business strategy perspective, the outlined strategies are aligned with IS projects, and from the IS development perspective, requirements are associated with both system and business strategy goals, allowing either to establish and trace the rationales behind IS projects.

Within the scope of SMBSC, a Goal is expressed as an Objective when an appropriate Measure to demonstrate its achievement can be defined (see Figure 2). An Initiative then encompasses all actions identified as required towards the achievement of the objective, within the constraints of given Milestones and Targets. After having identified initiatives, they could be analyzed for the realization through ICT, that is, consider how an initiative can be facilitated completely or to a certain extent by an IS solution. These considerations are defined as the system goals in GORE approaches, expressing stakeholders' needs and intentions, particularly for the early phases of requirements engineering [19].

After having identified initiatives by means of SMBSC, there is a need to decompose them and elicit system-related goals. We suggest a set of the following guidelines to be used to carry out the decomposition:

1. Elicit system goals concerning the planning of an initiative

2. Elicit system goals concerning the execution of an initiative

3. Elicit system goals concerning the control of the execution of an initiative

Any of the guidelines above may result in the elicitation of zero or more system goals supporting a given initiative from a SMBSC model. As an illustration, for the shopping mall case described in the previous section, the initiative Malls use modern technology in inventory management stems from goals derived from mapping to the consumer value of efficiency, which itself is mapped to the shopping value is convenience and addresses the desire for one-stop shopping [16]. This initiative can be supported, by following Guideline 2, via the IS goal Facilitate automated inventory management, which may be further operationalized with the functional system requirement The system shall store and retrieve the information on the available good items. In addition, the given initiative can be supported, by following Guideline 3, by the IS goal Facilitate an automated control of the minimal stock-level.

The above outlined approach constitutes a basis to identify goals for IT projects aligned with the outcomes of a SMBSC analysis. In addition, two other aspects of 
SMBSC can be considered when linking a consumer-centric strategy to a requirements engineering context: a) in SMBSC, objectives are related to measures, targets and milestones, which can be used to ensure and control the results of related IT projects, and b) the cause-and-effect links (i.e. dependencies) among the organizational perspectives in SMBSC propagate through Goals toward Objectives and further to Initiatives, and as such allow tracing the inter- and intra- dependencies of IT projects.

\section{Conclusions and Future Work}

To address the necessary link between consumers and the businesses that serve them as acknowledged in the introduction, we have proposed an integration of consumer values with business strategy. Particularly we have set an effort to relate Holbrook's Typology of Consumer Values [3] with Kaplan and Norton's Strategy Maps and Balanced Scorecards [4]. Holbrook's consumer values were mapped to the generic goals of a particular customer value proposition, Complete Customer Solutions, supported by the extended version of the SMBSC meta-model. Moreover, we have illustrated the applicability of the proposed mappings using the case scenario of a shopping mall. A strategy map, adhering to the complete customer solutions customer value proposition, was enriched with consumer values collected for shopping mall. Supported by the extended SMBSC meta-model and the traceability it provides, we have proposed guidelines for linking the initiatives derived from the refined strategy map requirements for the development of relevant IS solutions.

Steps forward in our research include exploring all four customer value proposition alternatives identified within the consumer perspective of strategy maps. We aim to explore other consumer value typologies and develop mappings to more business strategy approaches, while also evaluating their benefits within requirements engineering.

\section{References}

1. Morris, R.T.: The Theory of Consumer Demand. Yale University Press, New Haven (1941)

2. Drucker, F.P.: Management: Tasks, Responsibilities, Practices. Harper Paperbacks (1993)

3. Holbrook, M.B.: Consumer Value: A Framework for Analysis and Research. Routledge, London (1998)

4. Kaplan, R., Norton, D.P.: Strategy Maps: Converting Intangible Assets into Tangible Outcomes. Harvard Business School Press, Boston (2004)

5. Porter, M.E.: Competitive Advantage: Creating and Sustaining Superior Performance. Free Press, New York (1985)

6. Mauborgne, R., Kim, W.C.: Blue Ocean Strategy: From Theory to Practice. California Management Review 47(3), 105-122 (2005)

7. Frondizi, R.: What is Value? An Introduction to Axiology, 2nd edn. Open Court Publishing Company, La Salle (1971) 
8. Rokeach, M.: Beliefs, Attitudes and Values. A Theory of Organization and Change. Jossey-Bass Publishers, San Francisco (1968)

9. Schwartz, S.H.: Universals in the Content and Structure of Values: Theoretical Advances and Empirical Tests in 20 Countries. In: Zanna, M. (ed.) Advances in Experimental Social Psychology, San Diego, vol. 25 (1992)

10. Giannoulis, C., Petit, M., Zdravkovic, J.: Modeling Business Strategy: A Metamodel of Strategy Maps and Balance Scorecards. In: 5th IEEE International Conference on Research Challenges in Information Science (RCIS 2011). IEEE, New York (2011)

11. Kaplan, R., Norton, D.P.: The strategy map: guide to aligning intangible assets. Strategy \& Leadership 32, 454 (2004)

12. Kaplan, R., Norton, D.P.: Having trouble with your strategy? Then map it. Harvard Business Review 78, 167-176 (2000)

13. Kaplan, R., Norton, D.P.: The Balanced Scorecard: Translating Strategy into Action. Harvard Business School Press, Boston (1996)

14. Olve, N.G., Petri, C.J., Roy, J., Roy, S.: Making Scorecards Actionable: Balancing Strategy and Control. John Wiley \& Sons Ltd., West Sussex (2003)

15. Prasad, K.: Strategic Management: Text and Cases. PHI Learning Limited, New Delhi (2009)

16. Kim, Y.: Consumer Value: an application to mall and Internet shopping. Retail and Distribution Management 30(12), 595-602 (2002)

17. van Lamsweerde, A.: Goal-oriented requirements engineering: a guided tour. In: 5th IEEE International Symposium on Requirements Engineering, pp. 249-262. IEEE Press, New York (2001)

18. Anton, A.I., Potts, C.: A Representational Framework for Scenarios of System Use. Requirements Engineering 3(3), 219-241 (1998)

19. Yu, E.: Towards Modeling and reasoning Support for Early-Phase Requirements Engineering. In: 3rd IEEE International Symposium on Requirements Engineering (RE 1997), pp. 226-235. IEEE Press, Washington D.C (1997) 